\section{Video laryngoscopy as a device for removal of foreign body in the laryngopharynx}

\section{Abstract}

Background: foreign bodies in the hypo pharynx unusually present needle stick nature, and not tend to perforate the mucosa. The most common in this region are described EC spines of fish, but a wide variety of objects have been found. In this case were rice husk (oryza sativa). The following case report describe the foreign body removing with devices usually used for intubation.

Case report: a female patient, 28 years old, admitted to the emergency HRC with complaints of pain and irritation in the throat (herringbone). Was referred for endoscopy diagnosis of foreign body in the oesophagus and submitted to EDA under general anesthesia without visualizing abnormalities.

Conclusions: video laryngoscopy devices can be used to remove most foreign body in the hypo pharynx after several attempts by other techniques.

\section{Keywords}

Foreign body, video laryngoscopy, hypo pharynx, local anaesthetics, clonidine.

\title{
Background
}

Foreign bodies in the hypo pharynx usually present needle stick nature, and tend to perforate the mucosa and can reach vital structures such as major vessels or nerves, besides the possibility of suffering granulation, fistula formation and infection [1,2]. The most common in this region are described EC spines of fish, but a wide variety of objects have been found in this region [3]. The withdrawal proceeds by endoscopic devices or direct laryngoscopy, which presents high success rate. Other newly created devices may also be used for this purpose, such as video laryn-

Hermes Melo Teixeira Batista1, Gylmara Bezerra de Menezes Silveira², Italla Maria Pinheiro Bezerra1, Jéssica Feitosa Cavalcante $^{3}$, Luiz Carlos de Abreu ${ }^{1}$

1 Laboratory Design and Scientific Writing. Department of Basic Sciences, $A B C$ Faculty of Medicine, Av Prince of Wales, 821, 09060-650. Santo André, SP, Brazil.

2 Nurse at the Cariri Regional Hospital. Rua Catulo da Paixão cearense, S/N, Juazeiro do Norte, CE, Brazil.

3 Medicine Student from FMJ-Estacio/Juazeiro do Norte, CE, Brazil.

Contact information:

Hermes Melo Teixeira Batista.

Av Plácido Castelo A., 2001 Box 14, CEP63040-540, Laguna Seca, Juazeiro/EC, Brazil.

झ hermesmelo@oi.com.br 
goscopy. These allow a modification of the visual axis and images of good definition, facilitating the visualization of the larynx $[4,5]$.

This manuscript were performed with the approved by the ethics committe of the Regional Hospital of Cariri and is compliance with Helsinki Declaration and all research were conducted in accordance with these principles.

\section{Case presentation}

A female patient, 28 years old, admitted to the emergency HRC with complaints of pain and irritation in the throat (herringbone). Was referred for endoscopy diagnosis of foreign body in the oesophagus and submitted to EDA under sedation without visualizing abnormalities. Necessitated by an emergency IOT respiratory depression (procedure lasted approximately $120 \mathrm{~min}$ ). Referred to PACU and subjected to endoscopy the next day, again with no evidence of foreign body. As complaints persisted, conventional laryngoscopy was performed with suspected perforation of the hypo pharynx, with only view oedema. $60 \mathrm{~h}$ after the event and with persistent complaints of patient evaluation was requested anaesthesiology. After topical anaesthesia with lidocaine spray and bilateral blockade of the superior laryngeal nerve with $2 \%$ lidocaine without epinephrine, $2.5 \mathrm{ml}$ of each side, video laryngoscopy was performed with the patient awake. Clonidine $100 \mathrm{mcg}$ was administered in $10 \mathrm{ml}$ of SF0, $9 \%$ in order to achieve sedation and decreased salivary secretion. View of suggestive fishbone in the hypo pharynx, adjacent to the epiglottis (Figure 1). Grasping forceps used to remove the EC and the actual nature of the highlighted object "Oryza sativa" (rice husk), which pierced the mucosa of the pharynx and impacted in place, causing discomfort (Figure 3).

\section{Conclusion}

Video laryngoscopy devices are designed for difficult intubation [7]. Allow better visualization of the larynx by direct modify the visual axis and have high
Figure 1: Impacted foreign body. View by video laryngoscopy.

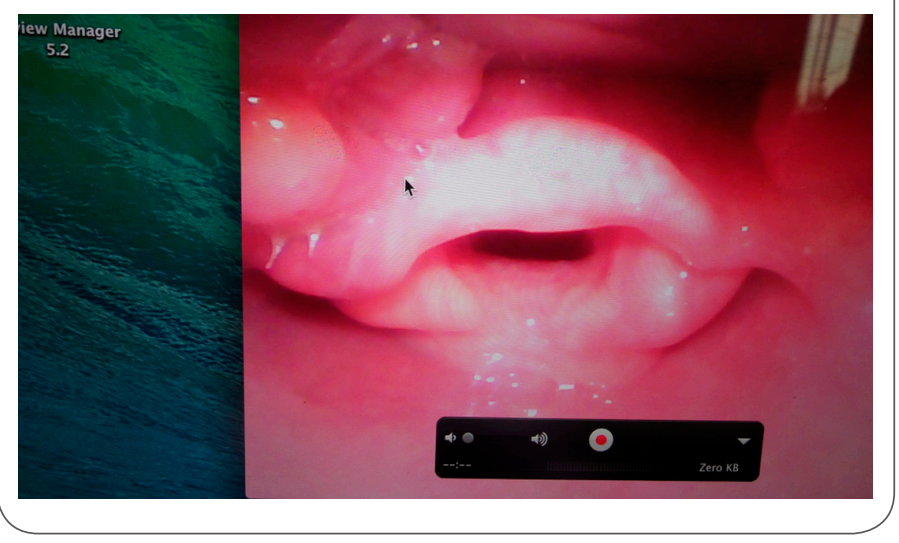

Figure 2: Hold the foreign body. View by video laryngoscopy.

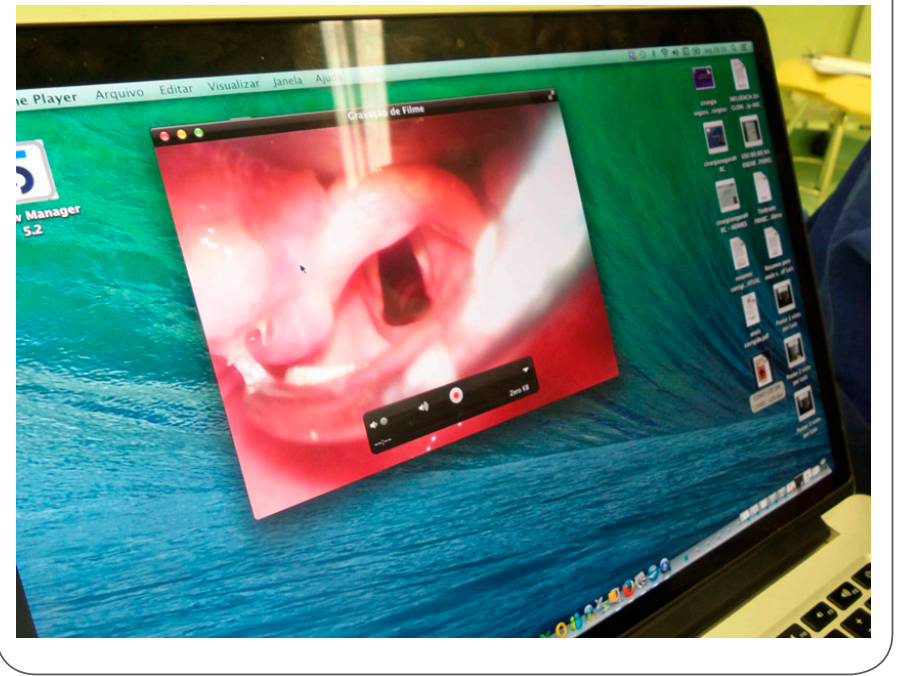


Figure 3: Removing the EC. View by video laryn-

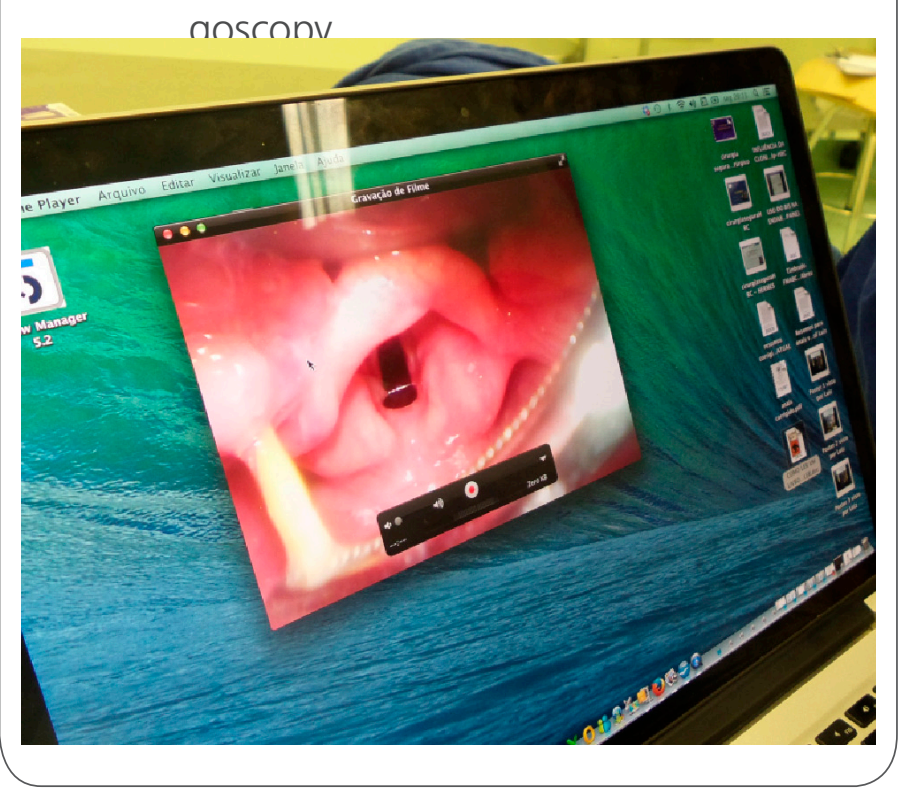

Figure 4: Bark Oryza sativa in gauze.

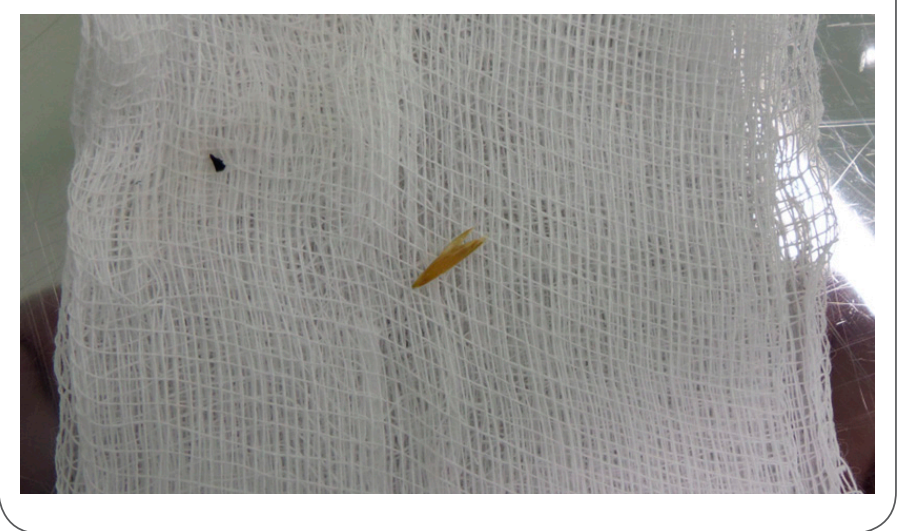

success rates. Consist of a miniature camera placed at the end of the laryngoscope blade, connected to a monitor or computer $[8,9]$. The device used by us it is disposable VDL, yellow trac ${ }^{\circ}$, which needs extra device to be used as a monitor $[10,11]$. This case describes the successful use of VDL in removal of foreign body in the hypo pharynx after several attempts by other techniques [12]. Also brings the particular type of uncommon foreign body in this situation [13]. We found no reports in the literature describing perforation and impaction of rice husk (Oryza sativa) in the hypo pharynx.

\section{Consent}

The patient signed Statement of Consent to report use for scientific purposes.

$$
\begin{aligned}
& \text { List of abbreviations used } \\
& \mathrm{VDL}=\text { video laryngoscopy } \\
& \mathrm{EC}=\text { foreign body } \\
& \mathrm{HRC}=\text { Regional Hospital Cariri } \\
& \mathrm{EDA}=\text { endoscopy }
\end{aligned}
$$

\section{Competing interests}

The authors declare no conflicts of interest. All research was conducted with proper investment.

\section{Author contributions}

All authors preparation of the manuscript and involvement in the case. HMTB Anesthesiologist involved in the case. All authors read and approved the final manuscript.

\section{Acknowledgements}

We thank Directors of Regional Hospital of Cariri in the position of favour of science and encouraging research. 


\section{References}

1. Argo FE, Cataldo R, Mattei A. New devices and techniques for airway management. Minerva Anesthesiol 2009, 75 (3): 141-9.

2. Behringer CE Kristenses MS. Evidence for benefit vs novelty in new intubation equipment. Anaesthesia 2011; 66 (suppl 2): 5764.

3. Kaplan MB, Ward DS, Bercy G. A new video laryngoscope an aid to intubation and teaching. J Clin Anesth 2002, 14 (8): 620-6.

4. Niforopoulos P, Pantazopoulos I Demestiha T, Koudouna $E_{\text {, }}$ Xanthos T. Video-laryngoscopes in the adult airway management: a topical review of the literature. Acta Anaesthesiol Scand 2010; 54 (9): 1050-61.

5. McGuire BE. Use of the McGrath video laryngoscope in awake patients. Anaesthesia, 2009; 62 (8): 912-4.

6. Fetterman BL, ML Shindo, Stanley RB, Armstrong WB, Rice $\mathrm{DH}$. Management of traumatic hypopharyngeal injuries. Laryngoscope 1995; 105: 8-13.

7. JT Johnson. Abscesses and deep space infections of the head and neck. Infect Dis Clin North Am 1992; 6: 705-717.

8. Kiukaanniemi MAJH, Pirila T, Jokinen K. Perforation in hypo pharynx and cervical emphysema deep Caused by blunt external trauma. Mil Med 1995; 160: 479-481.

9. Yugueros P, Sarmiento JM, Garcia AF, primed R. Conservative management of penetrating hypopharyngeal wounds. J Trauma 1996; 40: 267-269.

10. Durazzo MD, Pinto FR, Loures MSR, Volpi MS, Nishio S, Brandao LG, Cordeiro AC, Ferraz AR. The deep neck infections and their interest in the region. Rev Med Ass Brazil 1997; 43: 119-126.

11. Scioscia KA, MM April. Pediatric otolaryngology: cervical subcutaneous emphysema isolated. Am J Otolaryngol 1994; 15: 155-157.

12. Williams MF, Eisele DW, SH Wyatt. Neck needle foreign bodies in intravenous drug abusers. Laryngoscope 1993; 103: 59-63.

13. Pinto FR, Durazzo MD, Cordeiro AC, Ferraz AR. Cervical perforating foreign body:. Reporting casoRev. Assoc. Med Bras. 2000; 46

\section{Comment on this article:}
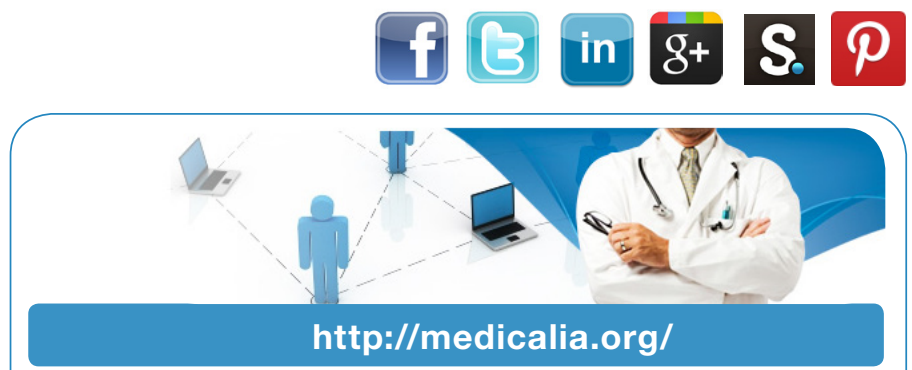

Where Doctors exchange clinical experiences, review their cases and share clinical knowledge. You can also access lots of medical publications for free. Join Now!

\section{Publish with iMedPub \\ http://www.imed.pub}

International Archives of Medicine is an open access journal publishing articles encompassing all aspects of medical science and clinical practice. IAM is considered a megajournal with independent sections on all areas of medicine. IAM is a really international journal with authors and board members from all around the world. The journal is widely indexed and classified Q1 in category Medicine. 